\title{
Assessing and Developing the Application of LEED Green Building Rating System as a Sustainable Project Management and Market Tool in the Italian Context
}

\author{
Walaa S. E. Ismaee ${ }^{1}$ \\ ${ }^{1}$ Lecturer, Architectural Engineering, British University in Egypt, El Sherouk City, Cairo Suez Desert Road. E-mail: \\ Walaa.salah@bue.edu.eg
}

Engineering and Project Management

Received November 10, 2015; received revision February 5, 2016; accepted February 6, 2016

Available online April 29, 2016

\begin{abstract}
The paper discusses the recent introduction of the LEED system to the Italian context in order to assess its role to promote sustainable building process in the Italian context, pointing out its potentials on one hand as well as their gaps and limitations on the other hand, and suggests means for its future development. The study discusses the application of LEED as a 'Sustainable Project management tool' to guide sustainable building performance. This requires investigating the following: its structure, tools, assessment criteria along with its benchmarks and references. It also discusses the application of LEED as a 'Sustainable building Certification and market tool'. This investigates the role and value of the LEED certification in the Italian Green market.
\end{abstract}

The research method is comprised of three parts. The first part is a comparative analysis of LEED categories against Italian national initiatives for sustainability. The comparison showed that most LEED categories are already mandated by national norms and directives but they may differ in their stringency creating some areas of precedence of LEED system or drawbacks. This streamlines the adaptation process of LEED system to the Italian context. The second part investigates LEED projects' market analysis. The result showed that the shift towards a sustainable building process is occurring slowly and on a vertical scale focusing on some building sectors rather than others. Its market diffusion in the Italian context faces challenges regarding the insufficient availability of green materials and products satisfying its requirements, as well as high soft cost of sustainability tests and expertise required. The Third part presents a practical review-citing the methodology and results of a survey conducted by the researchers in mid-2012. It is composed of a web-based questionnaire and interviews among a sample of LEED professionals in Italy. The result shows that LEED systems needs to develop its role as a guideline and decision support tool as well as its mechanism for measuring and evaluating sustainable building performance, so that better and reliable results can improve LEED position in the global marketplace.

The paper concludes that the application of LEED system in the Italian context still has much room for development both as a sustainable project management tool and as a sustainable certification and market tool. Yet, its future development lies in achieving a progressive development balance between three key factors: 1) preserving international standardization, 2) regional/local integration with sustainable building practices and green market, and 3) maintaining wider diffusion in the global marketplace. Hence, the research presents a set of recommendations for practitioners and researchers in the field in order to be able to improve the efficiency and efficacy of applying such a tool on the built environment.

Keywords: LEED green building rating and certification system, sustainable building process, sustainable project management tool, sustainable building certification and market tool.

\section{Introduction}

\subsection{Green Building Rating Systems}

Green building rating systems aim at promoting an integrated sustainable building process as well as individual practices. Appling LEED rating system to the Italian context is considered an interesting argument that offers a set of pressing questions regarding its adaptation methods to national and international commitments along with local regulatory context and operational processes.
This study attempts to open an early channel to receive practitioners' feedbacks to be able to narrow the gap between researchers and practitioners' viewpoints to develop the application of LEED green building rating system as a sustainable project management and market tool in the Italian context.

\subsection{The Italian Initiatives for a Sustainable Built Environment}

Italy as part of the European Union has solid initiative for sustainable development. It has many international 
commitments e.g. European Union's (EU) climate and energy package: the 2020 targets relating to greenhouse gas mitigation (GHG), renewable energy and energy efficiency as well as the Kyoto protocol targets (Ministry for the environment and Territory, 2013), (OECD/IEA, 2009). The trend towards Green buildings remains positive in Italy due to these key drivers: legislation and incentives, certifications, active role of trade associations and green building clusters (Bevini, 2009). Also, the Italian law 10/91, 99/2009, Budget Law 2006, 2007, 2008 and 2009 gave a lot of attention to the building sector and introduced some sustainable requirements for the built environment: 2002/91 and 2010/31, Energy Performance of Buildings Directive (EPBD), Green and White certification schemes, energy labeling and the follow up measures (OECD/IEA, 2009; IEA, 2010), along with sustainable initiatives which set an agreed upon definition on "High Performance Building" and "Near Zero Energy Buildings". They also raise the effectiveness target for certificates and inspections and their reflection on real estate market based on cost effectiveness and life-cycle analysis (Marszal, 2011). On the other hand, incentive mechanisms are awarded for energy efficiency and promoting renewable energy (OECD/ IEA, 2009).

Hence, it is noted that in the European context, the demand is increasing for both mandatory and voluntary certification schemes for both buildings and building products to evaluate and verify environmental performance and adopt a Life Cycle approach. First, for building products: 1) promoting the CE Certificate for building products, 2) ecolabels and particularly the Environmental Product Declaration (EPD) system (type III of ISO 14020, 2000), and 3) the Environmental Management and Audit Scheme (EMAS) (Berardi, 2011; the Ministry for the environment and Territory, 2013). Second, for buildings, the Italian Parliament approved the "Italian Guidelines for Energy Certification of Buildings" in 2009 and mandated the use of a "green report card" that calls for detailed analyses of buildings' energy performance (class and index represented in ACE) to be used for real estate market energy performance declarations (Bevini, 2009).

Moreover, Italy has embraced other types of buildings' energy certification schemes as well. First, Casaclima promoted in Bolzano region and focused mainly on energy savings. Second, Itaca protocol promoted in Piemonte region as a contextual adaptation of the SBTool offering a comprehensive set of sustainable criteria in a selfcertification form, and lately the introduction of the LEED system in May 2010 by the autonomous province of Trento (OECD/IEA, 2009). Yet, LEED certification has the advantage of being internationally recognized, and being the only third party verification and certification sustainable building performance certificate. This offers a standardized based of sustainable building performance assessment.

\subsection{Applying the LEED Rating System into the Italian Context}

\subsubsection{Defining the LEED system}

LEED is an abbreviation for 'Leadership in Energy and Environmental Design’ Green Building Rating System. It was developed by the U.S. Green Building Council (USGBC) in 1998 as a voluntary, consensus based and market driven green building rating and certification system (USGBC, 2009). The system aims at promoting the way projects are managed incorporating an integrated building approach, considering the whole life cycle of the building, and various levels of complexity of the building process, along with sub processes related to choice of green materials, products, systems and services.

Literature review presents several approaches for defining LEED system's goals: (a) applying LEED as a guideline tool to define and assist sustainable building practices, and support the decision making process (LEED, 2009; Rahardjati et al., 2011; Issa et al., 2010; Energy and Sustainability, 2010), (b) applying LEED as a measurement and evaluation tool to assess sustainable building performance (Energy and Sustainability, 2010; Steelcase WorkLab, 2009; Shikatani, 2010), and (c) applying LEED as a market tool for sustainable real estate market transformation (McManus, 2010; Energy and Sustainability, 2010) as shown at Fig. 1.

Types of LEED Rating systems are LEED for New construction and major renovations (NC), LEED for Core and Shell (CS), LEED for Commercial interiors (CI), LEED for Existing buildings operation and maintenance (EBOM), LEED for Neighborhood development (ND) and LEED for Homes (USGBC). The last two types of rating systems have different rating criteria, so they will not be included for discussion in this paper. LEED system is currently the world's second most widely diffused method. There are many countries which have adopted the LEED rating system, developing their own adapted versions e.g. India, Canada and Italy or using the US LEED certification system to certify the international system version (Fowler and Rauch, 2006 ), (IFMA, 2010).

LEED is considered one of the multicriteria Total Quality Assessment (TQA) methods, comprised of a point based system covering the whole building process. According to the USGBC, the allocation of points between credits in LEED 2009 is based on the potential environmental impacts and human benefits of each credit with respect to a set of impact categories. The system includes both 'qualitative' and 'quantitative' measures, 'prescriptive' as well as 'performance' measurement criteria, giving more weight to decisions affecting building operation (Eijadi et al., 2002). The sum total of credits obtained in all six categories determines the level of certification achieved and rates a building's performance in terms of environmental sustainability- certifications are awarded according to the following scale: Certified (40-49 points), Silver (50-59 points), Gold (60-79 points) and Platinum (80 + points).

\subsubsection{LEED System's Contextual Adaptations to the Italian Context}

Italy is the first European country to implement the LEED system. The GBCItalia launched in 2009 sponsors LEED Italia NC- which is currently the only adapted LEED version to the Italian context. This rating system is very similar to the US version of LEED NC 2009 adapted to the Italian climates, construction practices and regulations, including Italian-specific units and outline 
alternative compliance paths appropriate to the region (ENERBUILD, 2010).

Since 2008, the autonomous province of Trento has imposed the adoption of LEED rating system for assessing sustainable building performance for the construction of new province owned buildings. Additionally, it has assigned incentives to New Construction and Major Renovation LEED certified buildings (according to law $\mathrm{n}$. 825/2007) and Energy consumption lower than 60 $\mathrm{kWh} / \mathrm{m} 2$ per year (energy class B). It is also worth mentioning that till now, national incentives have been offered for energy savings only and not for applying a comprehensive sustainable approach (OECD/IEA, 2009; ENERBUILD, 2010).

\section{Research Method}

The research method is comprised of three parts. The first part is a comparative analysis of LEED categories against Italian national initiatives. The second part investigates LEED projects' market analysis. The Third part cites the results of a survey among LEED practitioners in the Italian context.

\subsection{Comparative Analysis of LEED Categories Against Italian National Initiatives for Sustainability}

LEED system is comprised of five main categories that represent sustainable criteria as shown in Table 1.

The trend towards green buildings in Italy is positive at an increasing rate owing to the European sustainable commitments and obligations, advances in green technologies, availability of green certificates and the spread of public knowledge and education concerning sustainability issues (Ministry for the environment and Territory, 2013; Bevini, 2009; Berardi, 2011). Hence, it can be observed from Table 1 that most LEED categories are already mandated by European legislations and directives but they may differ in their stringency. This streamlines the adaptation process of LEED system to the Italian context.

It is also noted that additional sustainable national initiatives were not covered by the LEED system but included in Italian national frameworks, this include: 1) Noise pollution- "Framework Act on Acoustic Pollution" 447/95, and 2) Electromagnetic pollution: Framework Act $36 / 01$ on the protection from exposures to electromagnetic fields (Ministry for the environment and Territory, 2013).

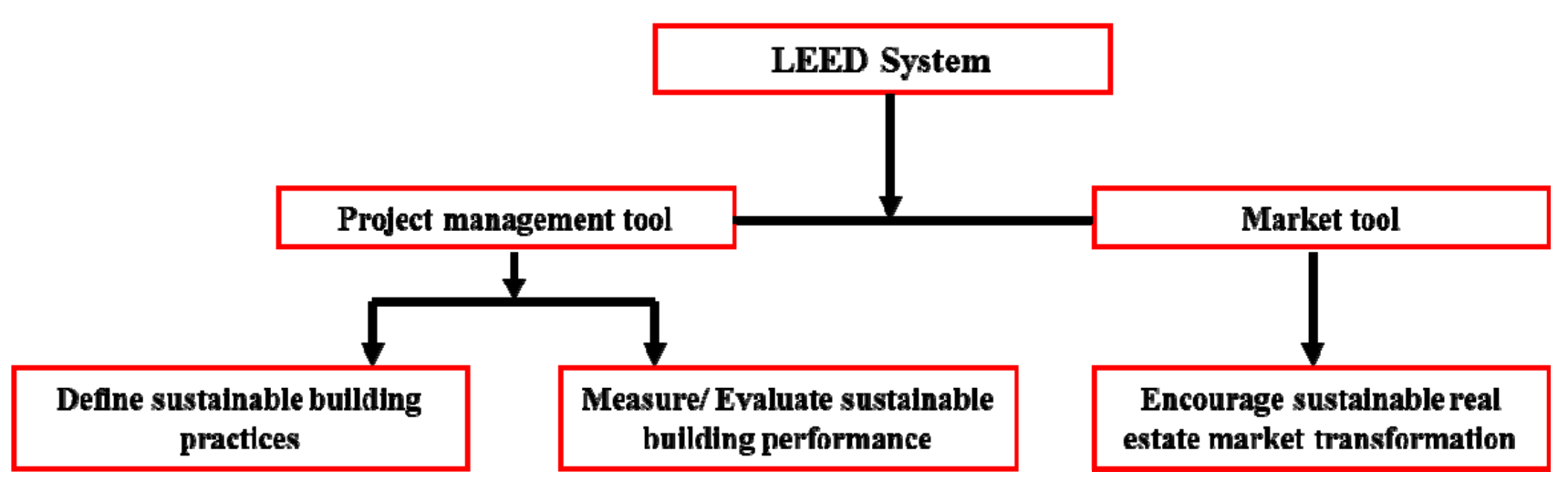

Fig. 1. LEED system dual function as project management and market tools 
Table 1. Comparing LEED categories to national sustainable norms and directives

\begin{tabular}{l}
\hline LEED Category \\
Sustainable Sites (SS) (26\%): it addresses the project's \\
interaction with its surrounding context in order to \\
minimize the building's negative environmental impacts \\
on ecosystems and waterways. Also, It discusses \\
construction related pollution prevention methods, site \\
development impacts, Brownfield development, \\
transportation alternatives, stormwater management, heat \\
island effect and light pollution reduction.
\end{tabular}

Water Efficiency (WE) (10\%): this category aims at encouraging designs that reduce potable water use both indoors and outdoors, using more efficient appliances, fixtures and fittings indoors and water-wise landscaping outdoors, as well as employing wastewater strategies.

Energy and Atmosphere (EA) (35\%): It seeks to increase energy efficiency while decreasing energy demand (Shikatani, 2010) through efficient design and construction, using efficient appliances, monitoring energy use, commissioning and measurement and verification, refrigerant management, renewable energy use and clean sources of energy generated on-site or offsite.

Materials and Resources (MR) (14\%): It discusses the "3R's" of waste management: Reduce, Reuse and Recycle, as well as the use of sustainable materials throughout the life cycle of the project, including regionally manufactured materials, materials with recycled content, rapidly renewable materials, salvaged materials, and sustainably forested wood products (FSC).

Indoor Environmental Quality (IEQ) (15\%): It aims at improving indoor environmental quality to create a healthy environment for building occupants, discussing environmental tobacco smoke control, outdoor air delivery monitoring, increased ventilation, construction indoor air quality, low emitting materials, source control, and controllability of thermal and lighting systems.
Italian National Norms and Directives

National norms and directives combine qualitative and quantitative indicators concerning biodiversity and preserving landscape culture.

The EU White Paper and the Italian General Transport Plan (PGT) for sustainable development of transports.

The definition of remediation interventions discussed by

Ministerial Decree 471/99, in compliance with Legislative Decree 22/97, article 17, with Act 426/98 (Ministry for the environment and Territory, 2013).

This field is wide open for new innovative technologies promoting; saving, re-using and recycling water activities to guarantee protecting and enhancing water quality, ecosystem and bio-diversity (Ministry for the environment and Territory, 2013).

Plans at EU level aim at reducing the exploitation of natural resources by $75 \%$ (factor 4) within 2030 and by $90 \%$ (factor 10) within 2050, in addition to increasing energy use and production from renewable sources (Ministry for the environment and Territory, 2013).

EU guidelines (Directives 91/156, 91/689 and 94/62) with the Legislative Decree 22/97 aim at stretching the lifetime of products and a shift towards dematerialization, resulting in general waste reduction and promoting local production markets, in addition to promoting recycling and treatment technologies (Ministry for the environment and Territory, 2013).

Framework Directive 62/1996/EC on air quality, endorsed by Law Decree 351/1999 for reducing atmospheric pollution.

The Montreal 1987 Protocol and its subsequent amendments along with (EC) 2037/2000 of the European Parliament and the Council of Europe restrict the use of Ozone-Depleting Substances (ODS) (Ministry for the environment and Territory, 2013).

\subsection{LEED Projects’ Market Analysis}

LEED system provides an internationally recognized third party certification through the independent Green Building Council (LEED, 2009). It is promoted as a market tool to attract investments in green market and provide differentiation for green buildings, standardization for sustainable building practices and banding for LEED certified projects in the global marketplace. This section aims at investigating LEED buildings' Market analysis in the Italian context regarding the following aspects: Geography- Certification level- Project Type and Type of ownership.

Total number of LEED projects in Italy is growing fast. Till the time of writing this research and according to USGBC online published project directory (http://new.usgbc.org/projects, retrieved on 22 March, 2013), total sum of LEED certified projects have reached 34 projects (with a sum total of 5,716, 266.5 gross square foot and 3,951, 513.7 square foot of total property area). As can be seen in Fig. 2, they are most widely concentrated in main cities as Milan and Rome. As for registered projects, the total number has reached 150 projects with a total area of $30,494,553.15$ gross square foot $(16,657,752.57$ square foot of total property area), it is comparatively focused in the main cities as well: Milan (38), Trento (13) and Rome (11). LEED certification is also spreading in other smaller cities but in a comparatively slower rate.

The most widely diffused type of rating systems is LEED for New Construction and major renovation as shown in Fig. 3, followed by LEED for Core and Shell. Other types of LEED rating systems are spreading in a slower rate.

'LEED Gold' certification level- ranging from (60-79 points) is the most widely obtained level of LEED certification as shown in Fig. 4, due to the stringent sustainable international as well as national commitments and obligations, which creates a high sustainable threshold for the Italian building industry. 
LEED systems attract stakeholders of private investments and for profit organizations for their brand name. Government projects are also major supporter for LEED projects (particularly in the autonomous region of Trento, where it is supported by both legislations and incentives mechanism as shown in Fig. 5.

Commercial office buildings are the most widely diffused project type acquiring the LEED certification, followed by private institutions, then governmental buildings for public use as shown in Fig. 6.

The result of LEED projects' market analysis shows that LEED adopts a focalized vertical market approach. It focuses more on commercial and office buildings in main cities and large scale projects, and mostly private ownership) in order to attract investments using its certification's brand name.

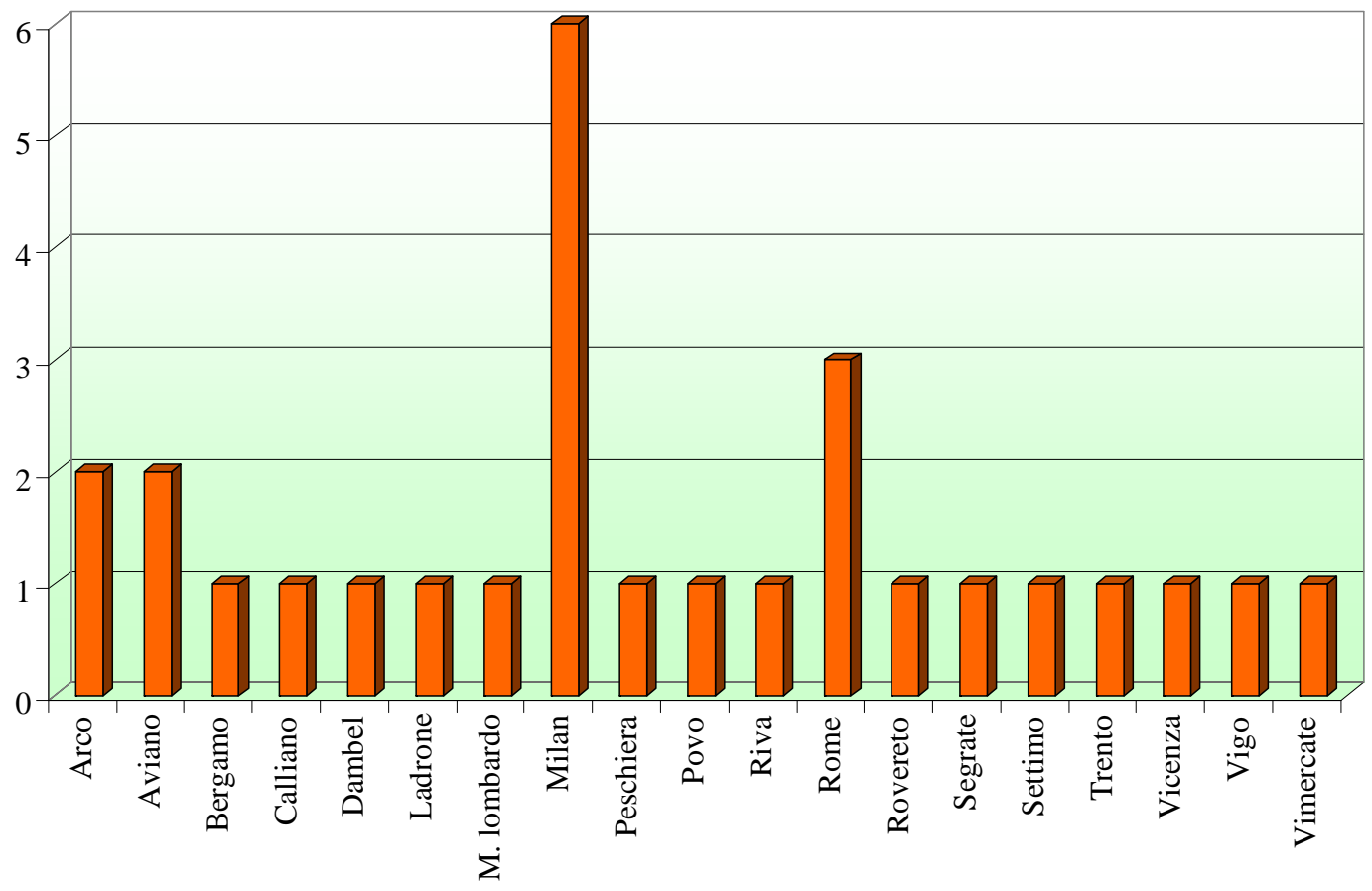

$\square$ No. of LEED certified projects

Fig. 2. LEED certified projects

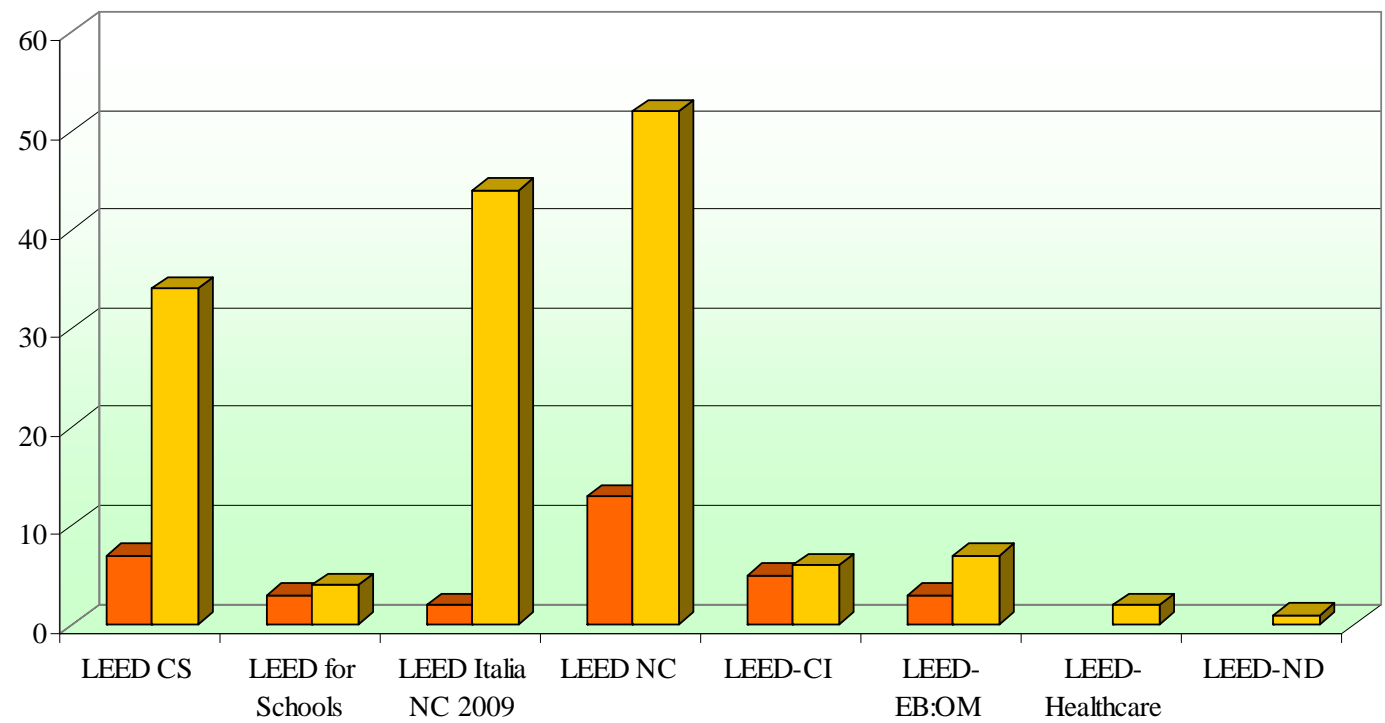

$\square$ No. of LEED certified projects

$\square$ No. of LEED registered projects

Fig. 3. LEED projects’ types of rating system 


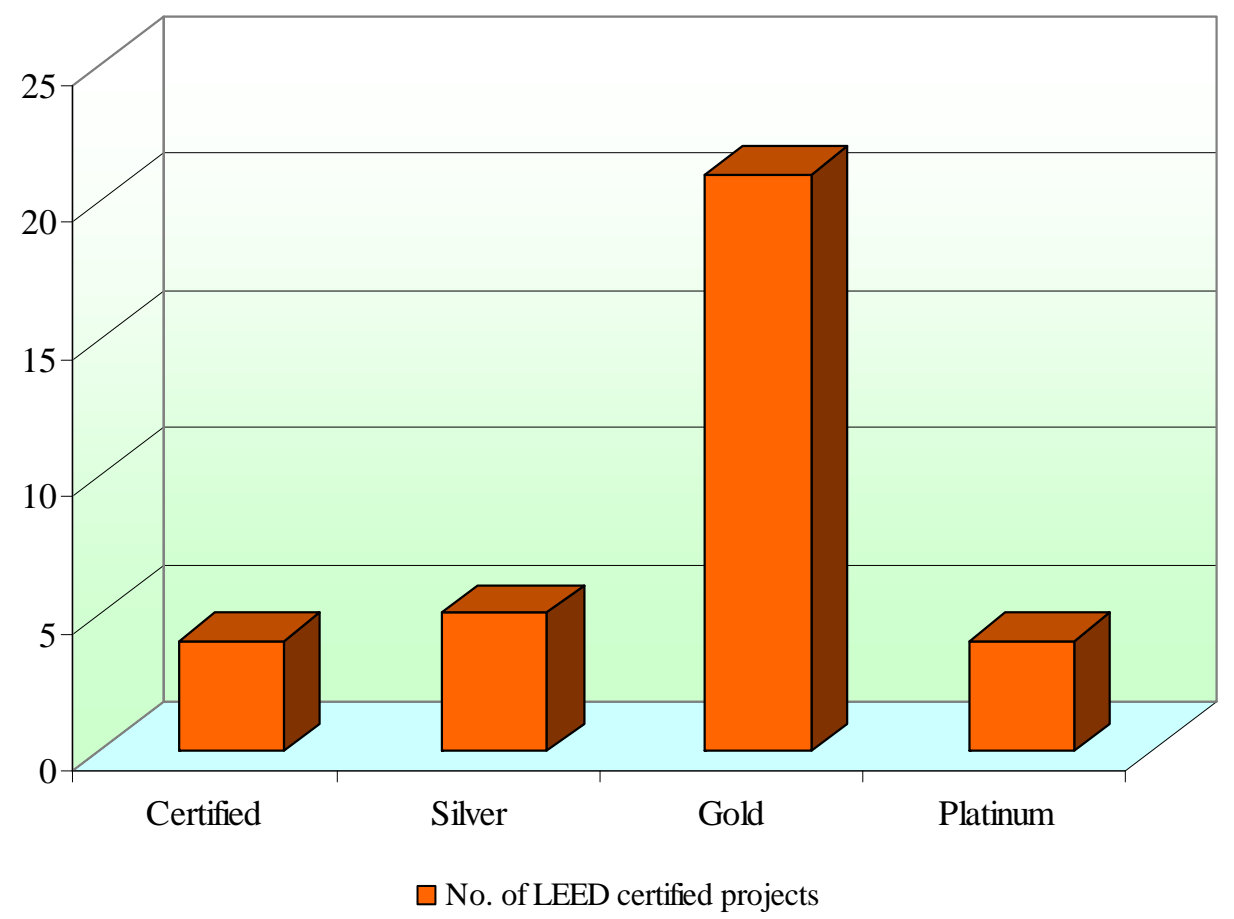

Fig.4. Certification level obtained by LEED projects

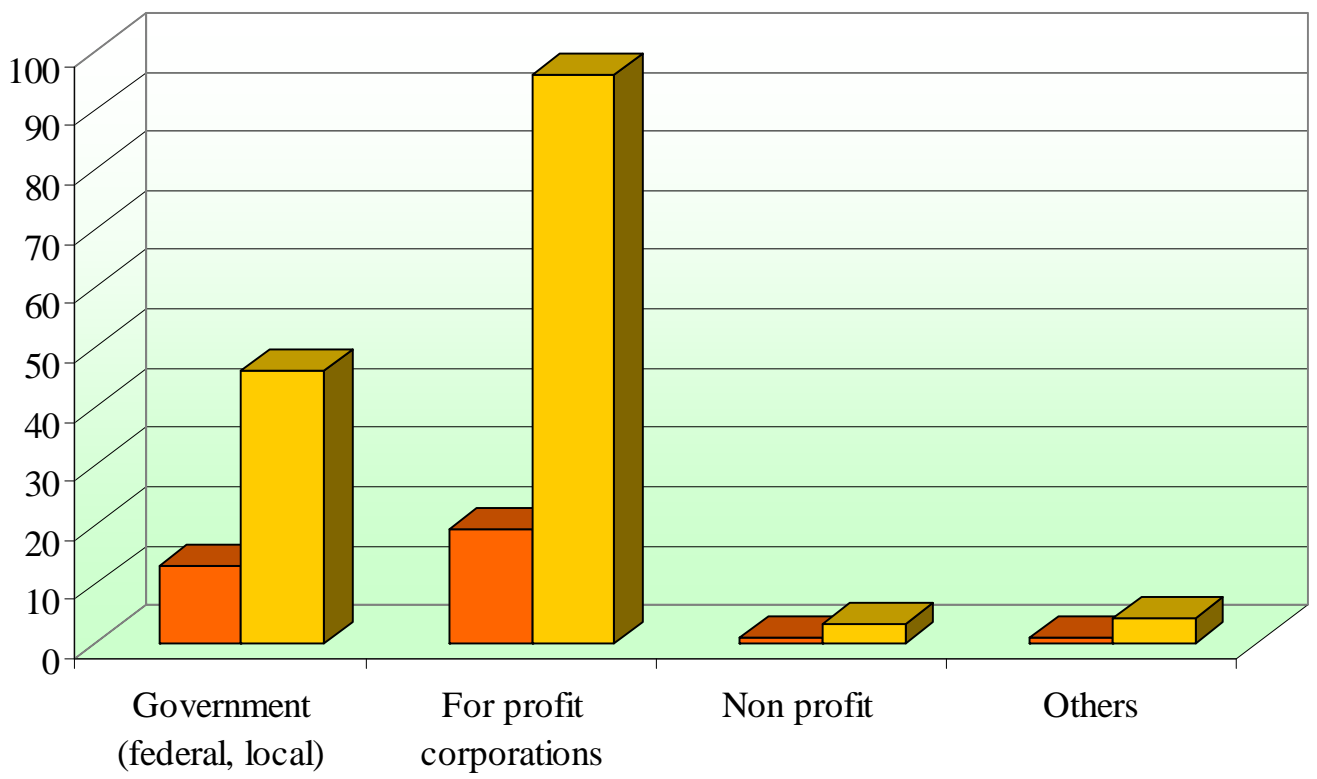

$\square$ No. of LEED certified projects

$\square$ No. of LEED registered projects

Fig. 5. Type of ownership for LEED projects 


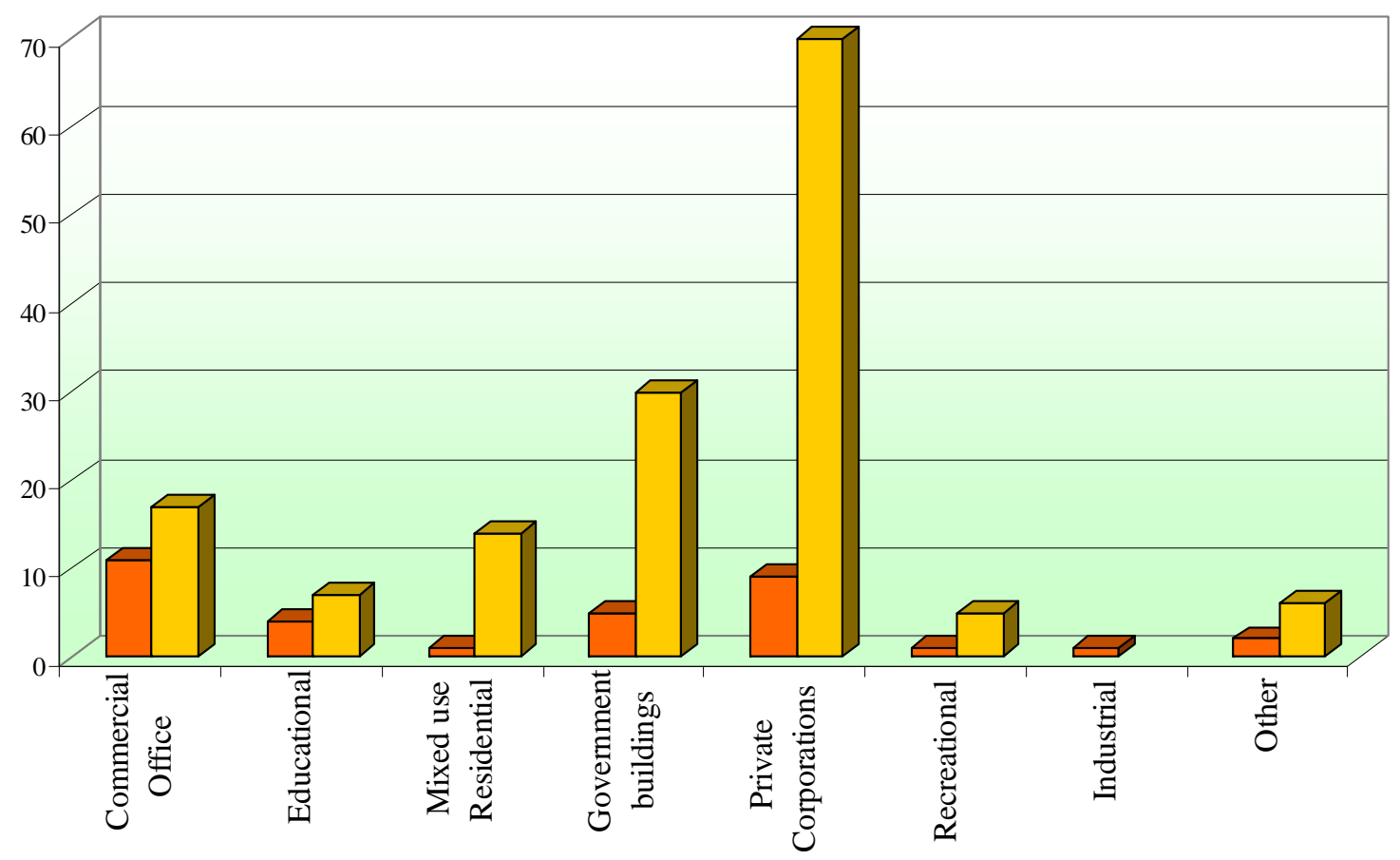

$\square$ No. of LEED certified projects

$\square$ No. of LEED registered projects

Fig. 6. LEED projects' types

\subsection{Practical Review: Practitioners' Evaluation of Applying the LEED Rating System in the Italian Context}

The researchers used an online web-based questionnaire along with conducting ten interviews with LEED practitioners in the Italian context to investigate the practical perspective from applying the LEED rating system in the Italian context. They were carried in the period from May to July 2012.

\subsubsection{The Online Questionnaire}

The online questionnaire was carried on a sample of 150 LEED practitioners, with the following link http://www.esurveyspro.com/Survey.aspx?id=bdab1d67cbc2-40ac-817e-0f39672266bc, according to the previously published names on the electronic site for the Green Building Council www.usgbc.org/LEED/Accredited_Pros/accredited_pros_ directory.asp (retrieved in May, 2012). It received a percentage of $18 \%$ responses, with $(63 \%)$ completed responses and $(37 \%)$ incomplete ones. The studied sample included several specializations, e.g. Designing and Planning, Research and Development, Management and Consultancy, Engineering and Construction and Others as shown in Fig. 7 and included a range of different LEED specializations (but mainly dominated by LEED AP for NC as shown in Fig. 8.

\section{Questionnaire Design}

The questionnaire included 26 questions (including 3 open ended ones and the rest single and multiple choices answer). It is organized in a hierarchical order, first relating LEED system application to the wider contextual scope of building industry in Italy, then shifting to more detailed levels of project application, then discussing issues related to credits' application and finally investigating LEED market performance.

\section{Analysis}

\section{Reason for choosing the LEED system}

Analysing the results obtained in Fig. 9 show that LEED rating system is chosen mainly for its reputation in the global marketplace. It is perceived to increase sustainable building performance by more than 50\% through introducing sustainable management practices, as well as measurement and verification procedures for sustainable building performance.

\section{Applying LEED as a sustainable project management tool}

Applying LEED credits is perceived to be of medium difficutly (individual practices). Nevertheless, managing projects under LEED certification is perceived more difficult (the whole process) as shown in Fig. 10. During interviews, practitioners highlighted the existence of some challenges and drawbacks for using the LEED system. First concerning project management practices, complains around the system's structure which does not provide definitive limits of operation nor does it provide a 'Know how' to integrate LEED requirements in the ordinary building process or perform an integrated building process to explore synergies and trade-offs. This represents a challenge especially for first time users of the LEED system. 
Both calculation and simulation methods were perceived difficult and/ or expensive to perform as shown in Fig. 11. Another concern was raised during the interviews, stating that using new tools to support a sustainable decision making process is still not a mature practice because computer simulation models are used for certification reasons instead of experimenting sustainable design options.

Results of the interviews complemented the survey results shown in Fig. 12, and they both indicated that applying LEED system enhanced green education and communication among team members, particularly within the boundary of the applied version and its requirements, but LEED online is rather considered an upload tool rather than acting as a user guidance, not promoting direct interface for step by step guidance along project phases. This may not help avoiding a lot of timely, costly change orders, or on the other hand, it might cause inability to gain credits or make best use out of the system- this problem is assumed to be diminishing the more LEED experience gained, and hopefully with more advancements in the LEED online tool.

Fig. 13 shows that LEED system is perceived to have higher sustainable requirements rather than national/regional norms and/or standards, but for the purpose of managing projects, both types of references were used to comply with the requirements of local building codes as well as with LEED system's requirements.

Fig. 14 and 15 show that extra cost for applying LEED system was estimated between 5-20\%. Extra cost includes both hard and soft costs. Hard cost includes cost of obtaining sustainable buildings according to LEED requirements, documentation and certification cost as well as the rest of LEED requirements like energy simulation, commissioning...etc., while soft cost includes extra time, effort or special expertise of design team members to satisfy LEED requirements. LEED Energy and Atmosphere category was perceived to result in the greatest future payback, within around 5-10 years.

Testing energy and materials' credits shown in Fig. 16 reveals that it is on the contrary with international studies (Lavy et al., 2009), LEED Energy and Atmosphere category was found to constitute the more achievable point category, while on the other hand, MR category remains among the most challenging ones. While testing adaptability on the scale of individual credits was complemented through the interviews, indicating that some credits exceed national building regulations and current best practices. Some credits were easier to apply in the Italian context due to already existing strong sustainable base for national building regulations. Other credits require regional variation, or were relatively difficult to obtain due to perceived capital cost, e.g. onsite renewable energy sources- although there exist some national incentives to reward onsite renewable energy especially from photovoltaic cells but it is not enough to satisfy the required threshold for project energy demand as required by LEED system. Additionally, Commissioning services and simulation requirements require extra cost, schedule and expertise which vary according to building type, scale and complexity- but by the time of writing this research, probably they shall be considered common building practices to raise the quality of sustainable building performance.

\section{Applying LEED as a sustainable building certification and market tool}

Fig. 17 and 18 show that the national market requires more potential to comply with LEED system's requirements. Then focusing on sustainable energy and materials market shows that some LEED Energy and Atmosphere credits are substantially easy to achieve owing to the high energy efficient baseline required by national/regional building codes, yet methods of compliance differ, and this requires additional effort by design team to direct energy efficiency practices and performance measures to comply with both national and LEED credits' requirements. Interviews pointed out that it is still not a common practice to perform the required simulation and calculation for Measurement and Benchmarking criteria, in addition to some difficulty to obtain some sustainable building materials, products and services according to LEED requirements- they are either difficult to obtain, document and/or expensive- but by time the market is gaining more acceptance and this problem is diminishing.

It is also important to note that adoption of new green practices varies according to various contexts due to perceived high cost and complexity to obtain some credits (Gauthier and Wooldridge, 2011; Thilakaratne and Lew, 2011) e.g. on the international scale- the use of native plants, local materials, and site protection strategies have been found easier to implement and adopt than the use of green roofs, on-site wastewater treatment and material life-cycle analysis.

Fig. 19 shows that the more challenging barriers for the diffusion of LEED system in the Italian market were perceived to be low financial and/or structural incentives, lack of stakeholders' interest, as well as the complexity of the certification process requiring more time, and money premium- which represents a challenge especially for smaller size and budget projects.

\section{Potentials and drawbacks of applying LEED system}

The following points were highlighted as potentials for applying LEED system:

- Reviewing and improvement of sustainable project management process.

- Diffusion of information on sustainable and innovative practices.

- Management control of the project to its construction.

- International visibility and better market position.

- Durability and savings for energy and materials.

- Promoting an Integrated Design approach (but further development is required as indicated in the interviews).

While on the other hand, some drawbacks were pointed out as follows:

- If LEED system is misapplied or applied through a single market perspective without considering 
the actual quality of the process taking a short term rather than a long term perspective- driven by point chasing and seeking easily achieved credits, it is likely to cause more unsteadiness in the construction industry.

- Another concern was raised regarding the inflexibility for applying LEED system to all project sizes, types and contexts. According to practitioners, it was more reasonable to apply it on large scale/complex projects with huge investment size.

- A concern related to the contextual adaptation of the LEED system in the Italian context revolved around the lack of a detailed assessment of regional priorities specific to various sectors of the construction process, paying more attention towards the multidisciplinary nature of the building process and adaptability methods to various types and scales of buildings.

- Another contextual related issue has pointed out the need to establish direct interface with other national sustainable programs, certification systems and incentive mechanism, along with studying specifics related to the Italian construction market in order to be able to establish radical contextual adaptationsespecially that the European context has advanced initiatives for sustainability.

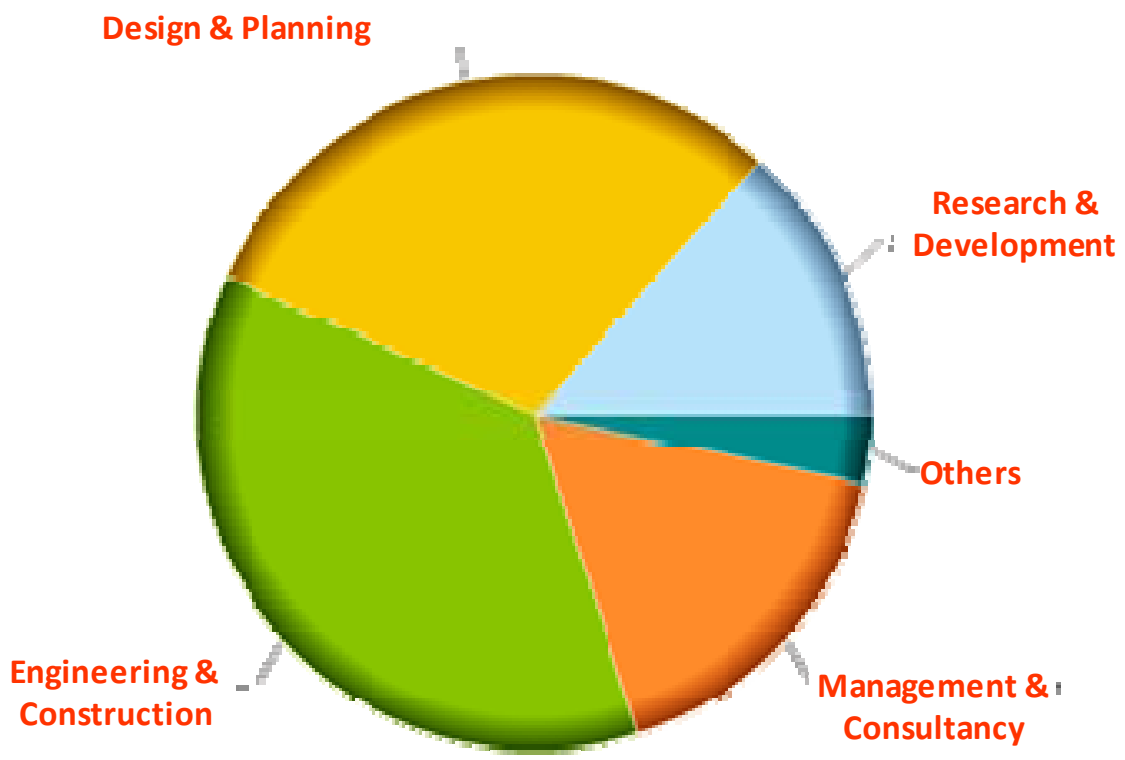

Fig. 7. Practitioners’ background

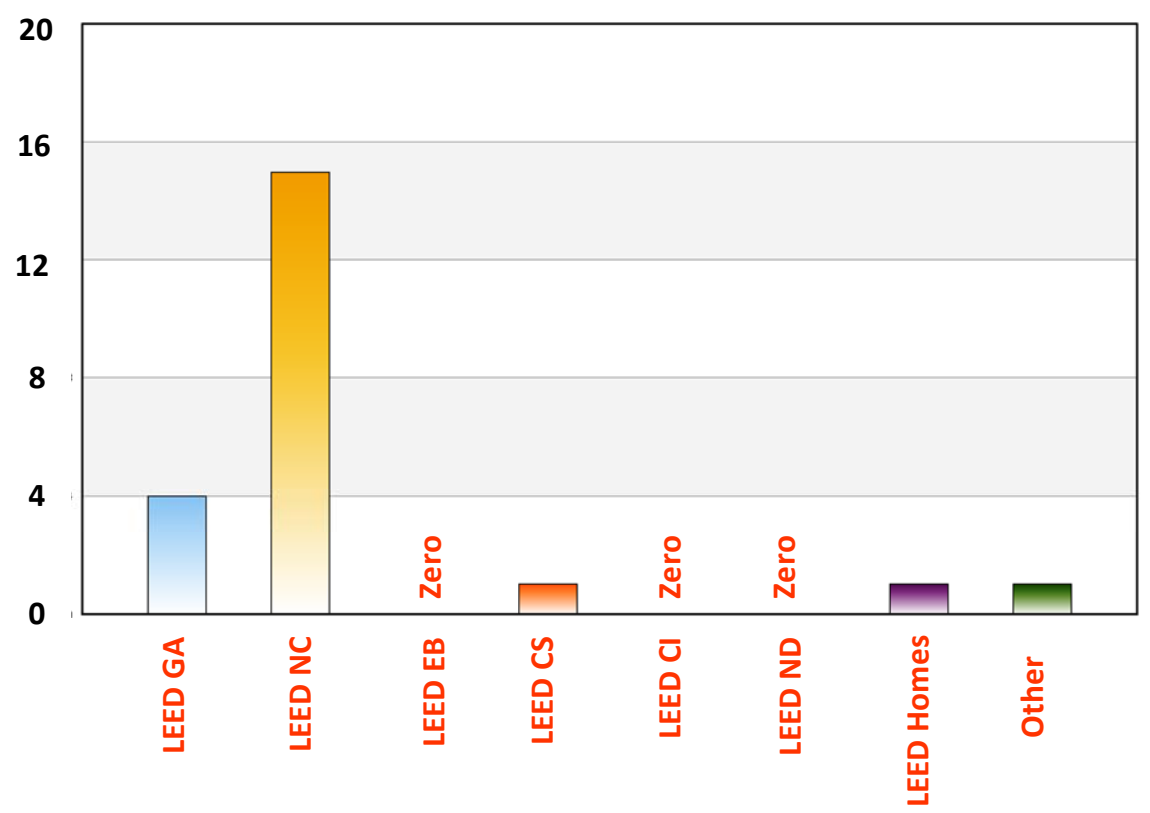

Fig. 8. LEED specialization participating in the study 


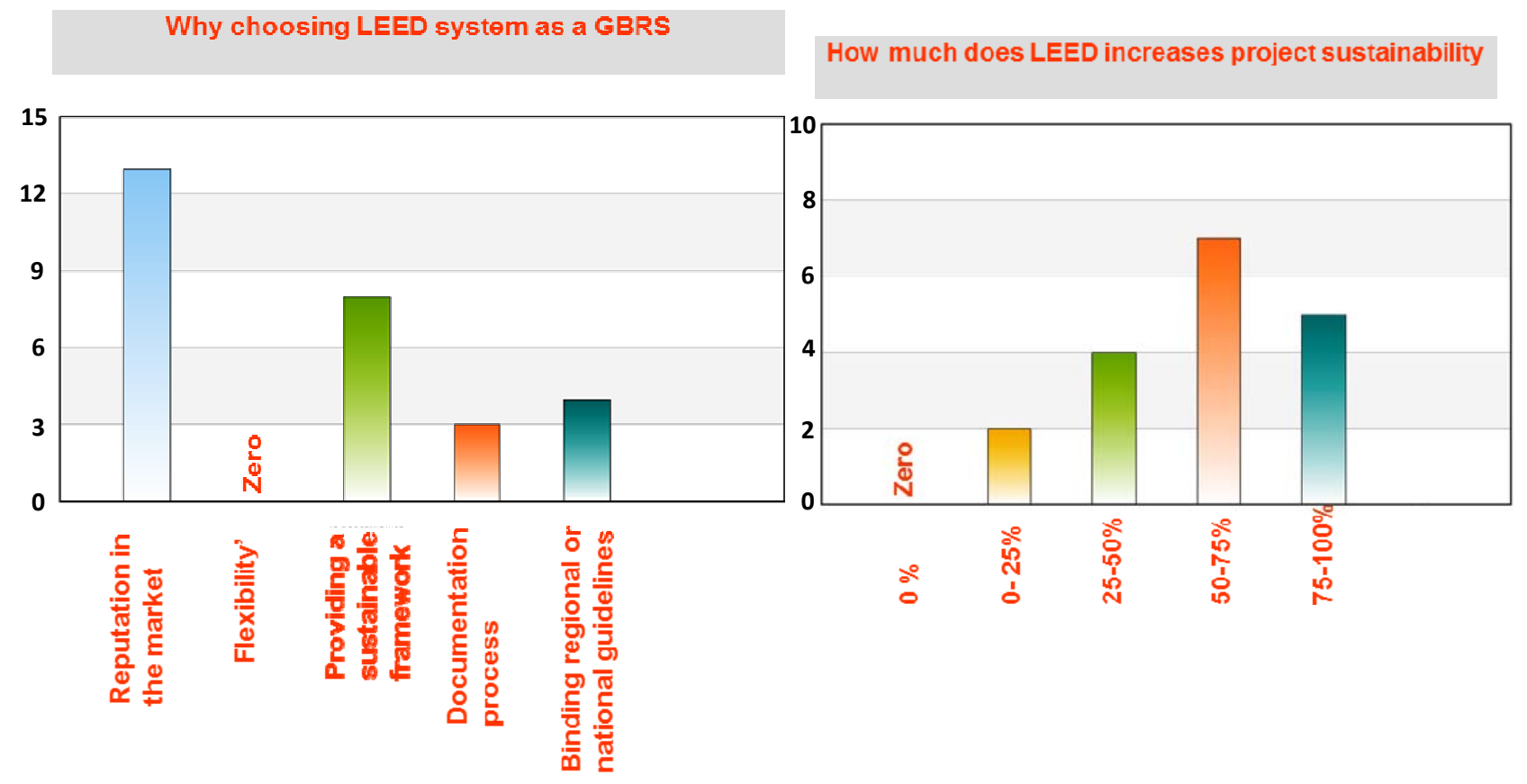

Fig. 9. Reasons for choosing LEED system
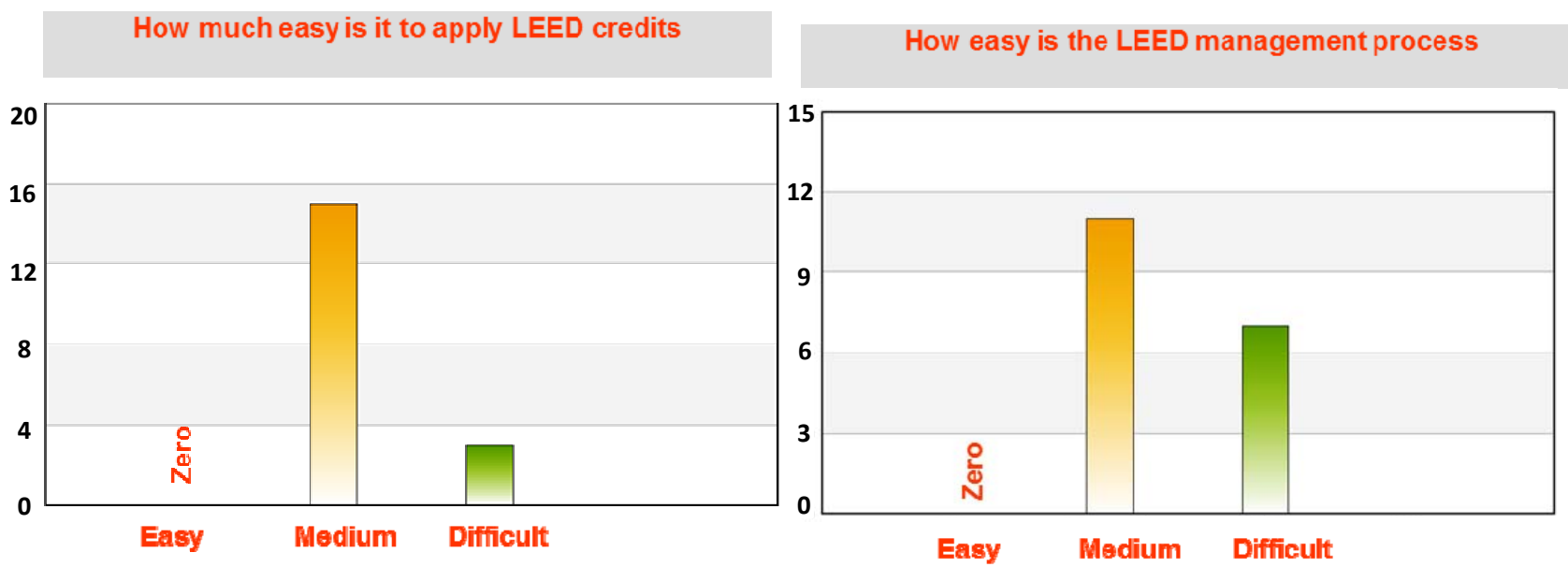

Fig. 10. LEED management process versus practices

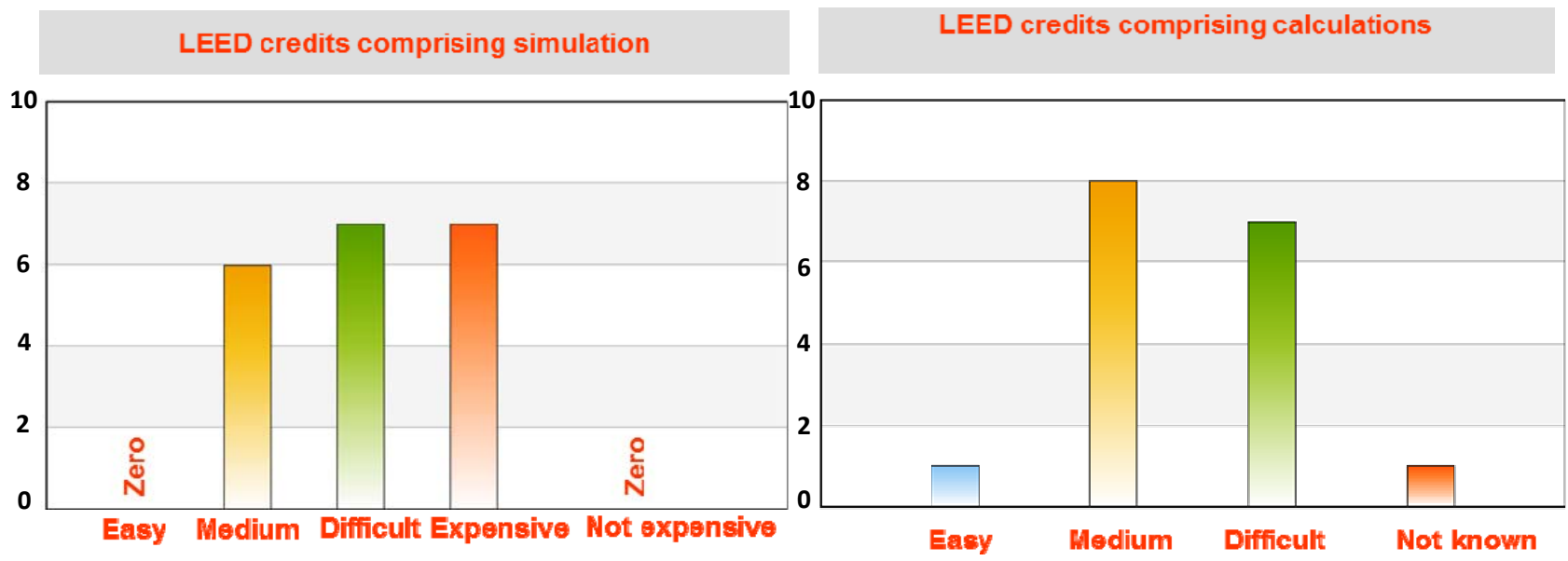

Fig. 11. LEED simulation and calculation credits' requirements 


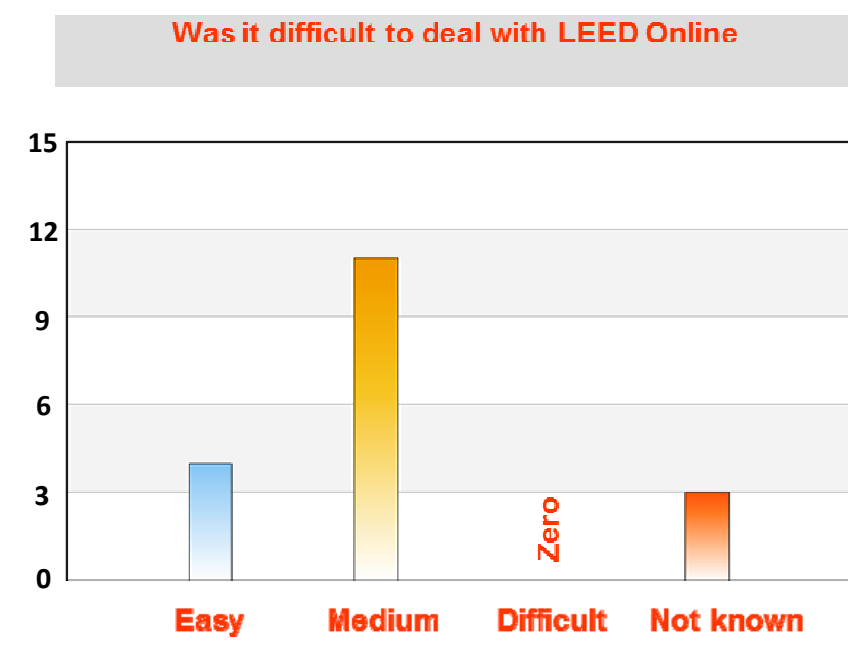
among project team members

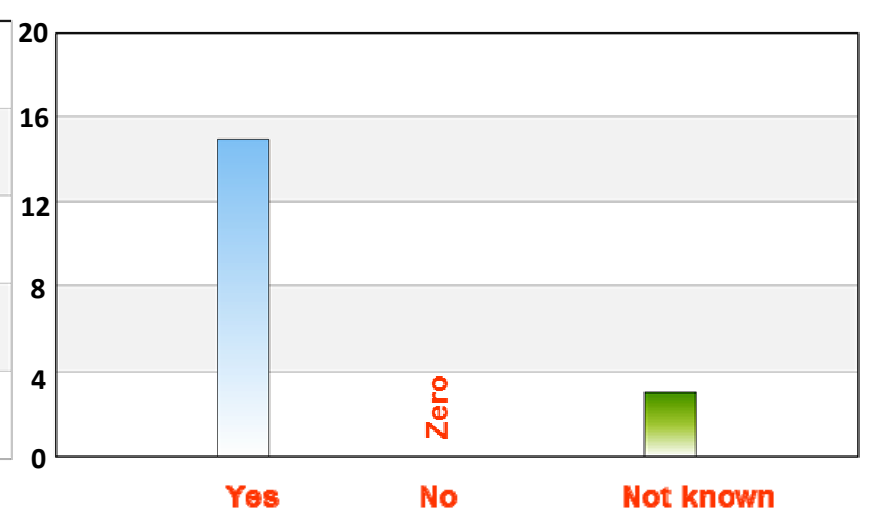

Fig. 12. LEED communication channels and enhancing green education

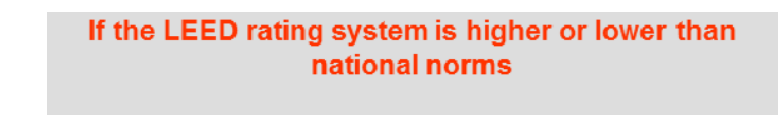
local/regional ones
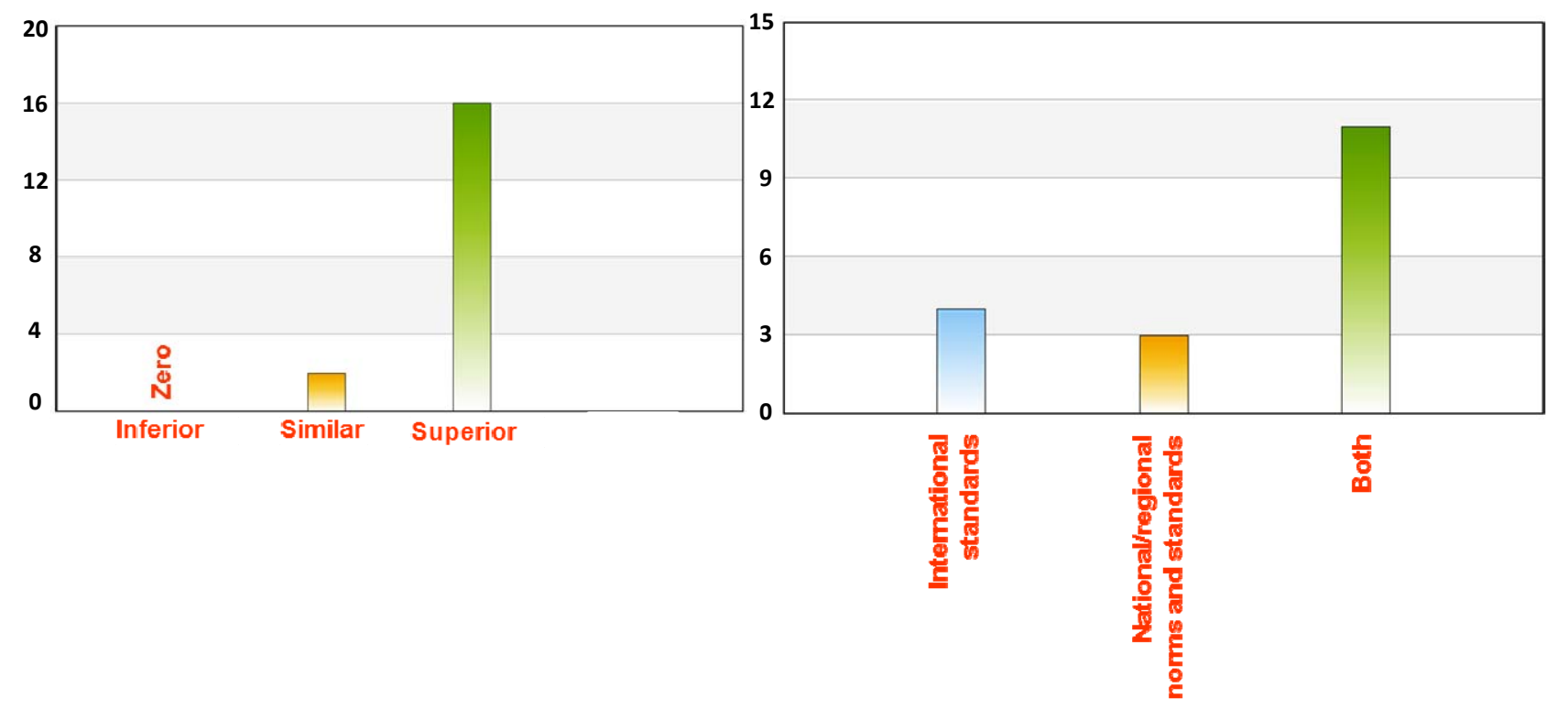

Fig. 13. Compliance path using LEED requirements or national norms 


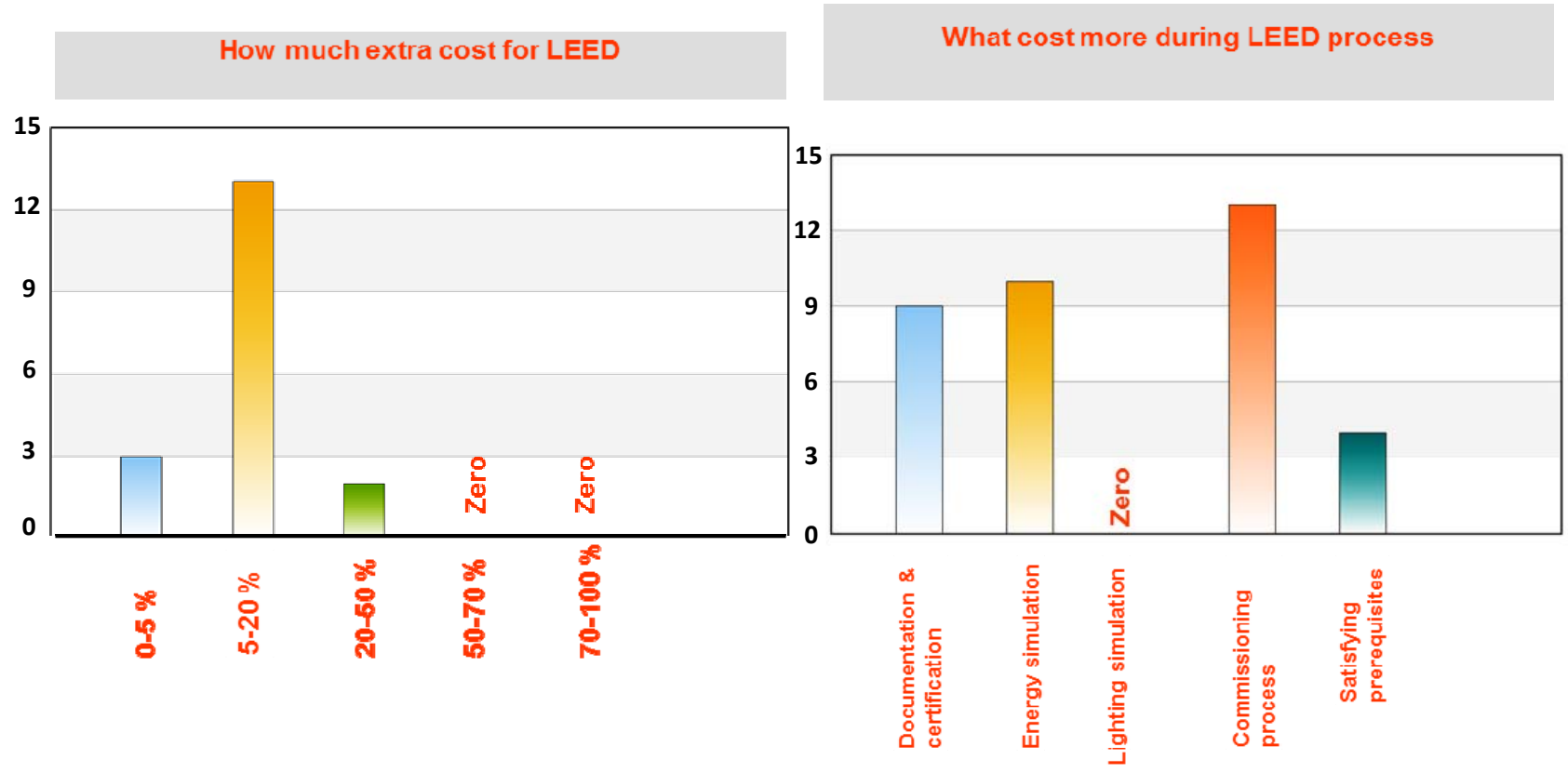

Fig. 14. Extra cost premium for LEED certification

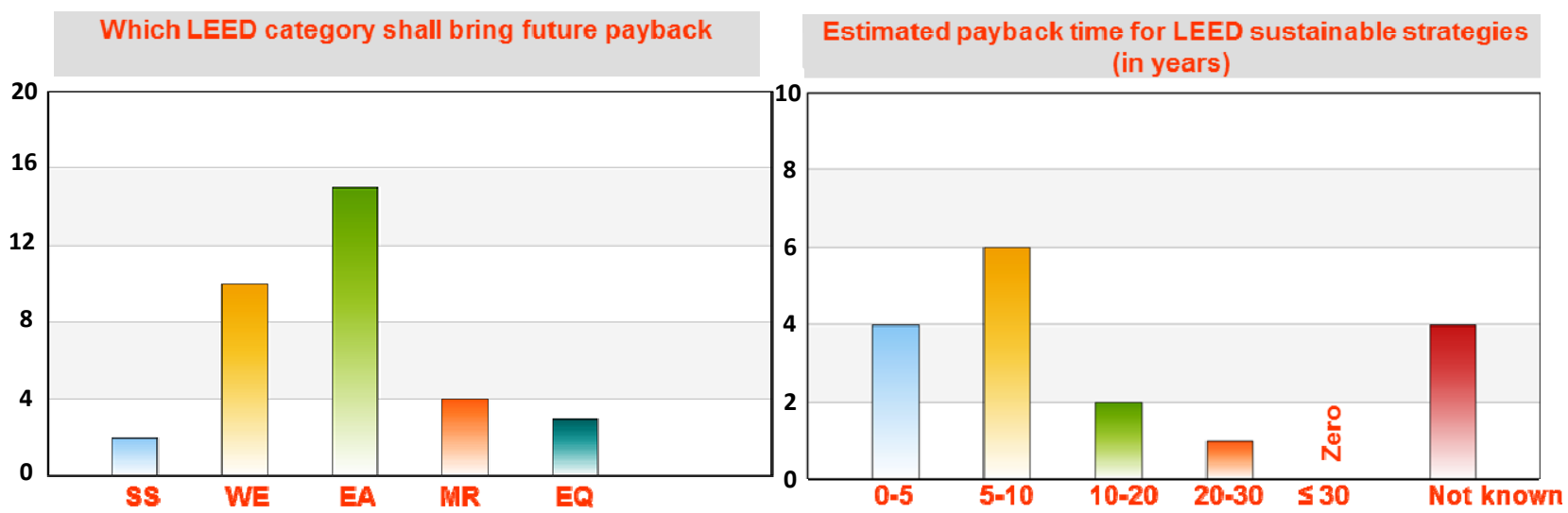

Fig. 15. Future payback for LEED categories

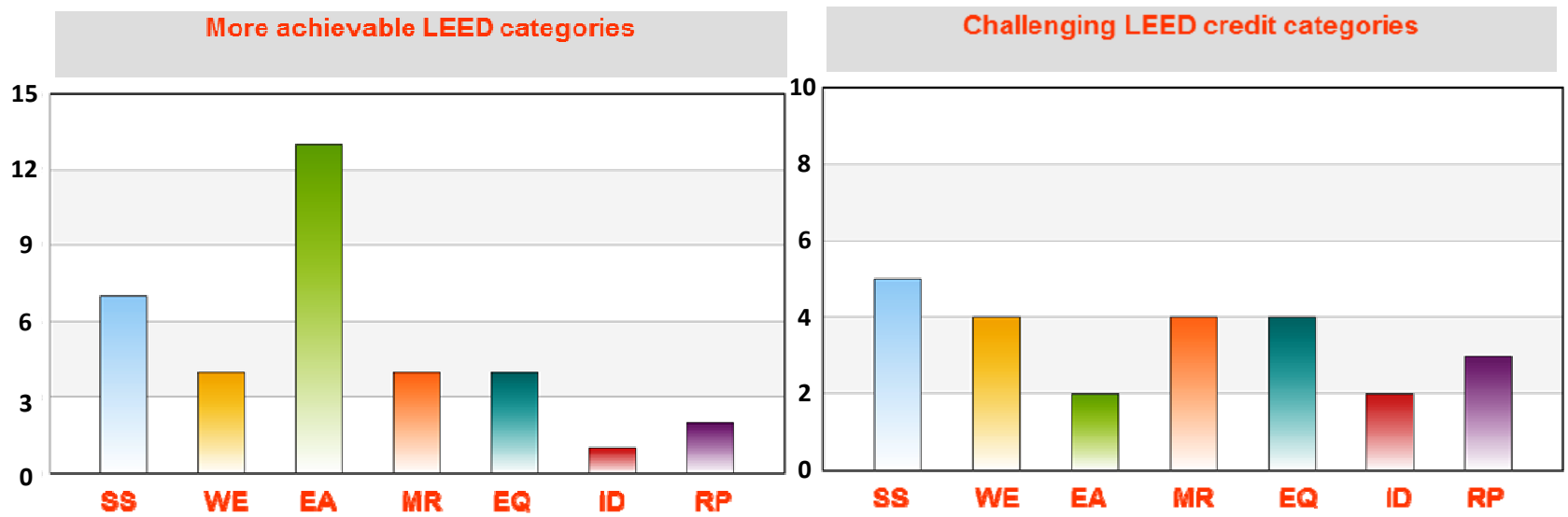

SS: Sustainable sites, WE: Water efficiency, EA: Energy and atmosphere, MR: Materials and resources, EQ: Environmental quality, ID: Innovation in design and RP: Regional priority

Fig. 16. Perceived easily and difficult LEED credits 
If the national LEED market is ready for the LEED certification

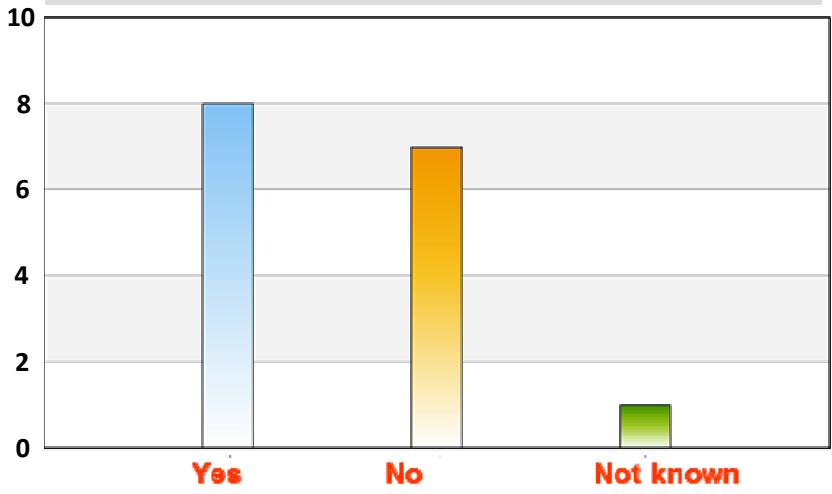

Fig. 17. LEED and national green market

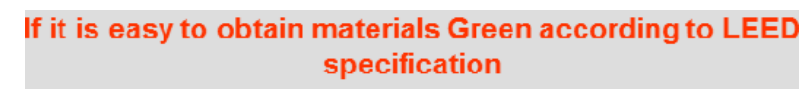

if LEED helps diffuse green products \& technologies in the market
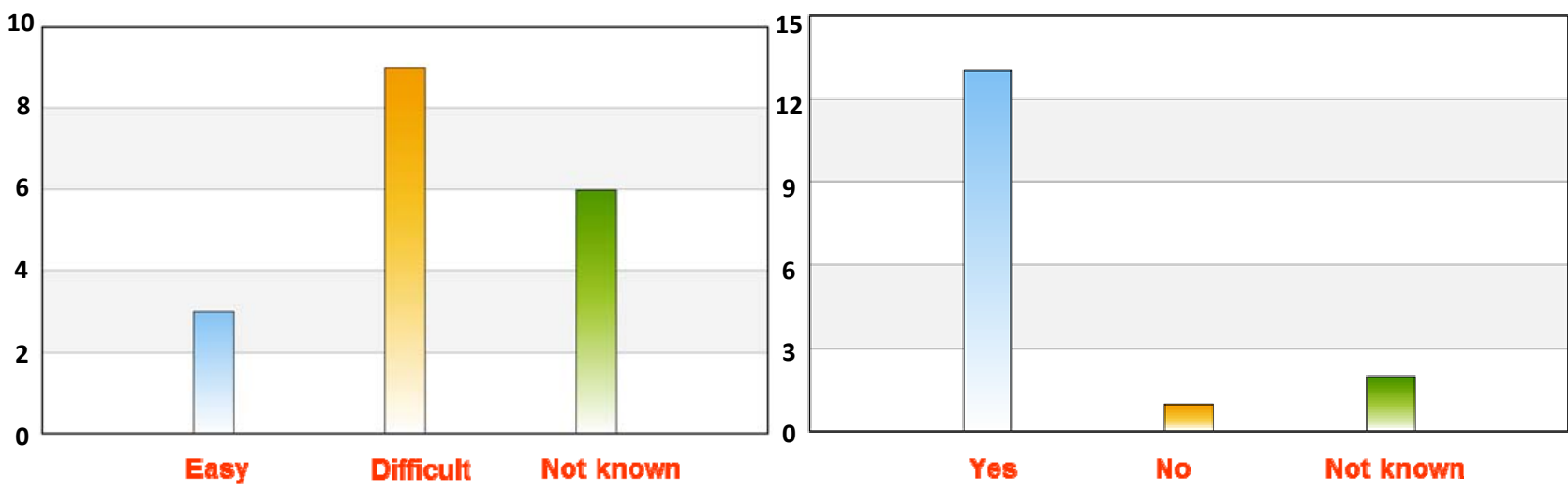

Fig. 18. LEED and green building materials' availability 


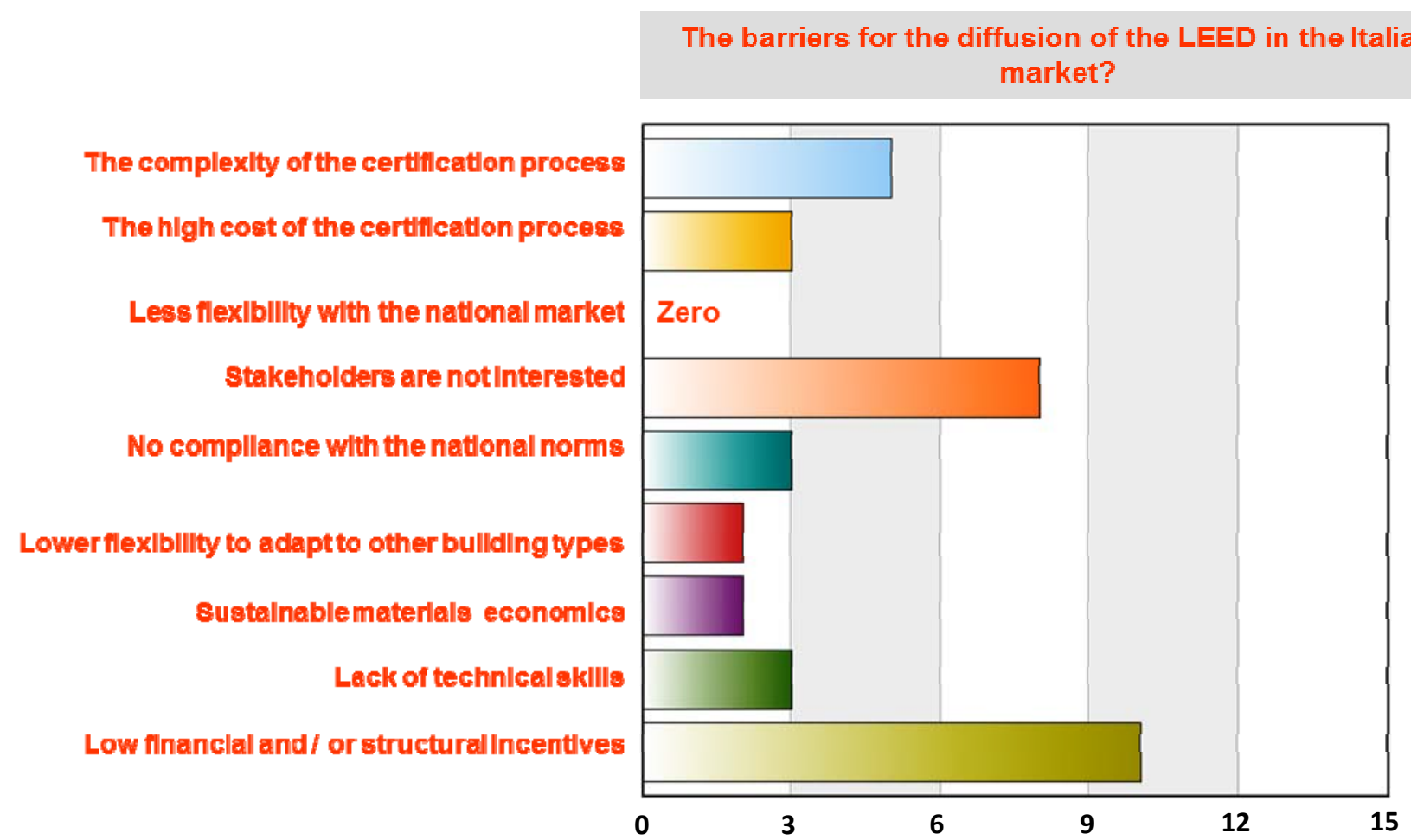

Fig. 19. Barriers for the diffusion of LEED system

\subsubsection{In-person Interviews}

The research cited additional ten in-person interviews with LEED practitioners in the Italian context. They agreed with many of the conclusions indicated by the questionnaire in addition to stressing some issues related to the following points:

1) LEED system provides a robust framework, but it is still a difficulty to achieve an integrated building process using LEED system's guidelines, 2) using new tools to support a sustainable decision making process is still in its infancy, e.g. computer simulation models are used for verification instead of experimenting design options, and LEED online does not act as a guideline, it only provides letter templates for data uploading, 3) Currently, the Italian market is still not ready for the LEED certification because it is still not easy to find green materials, products and services- according to LEED requirements but the market is gaining more acceptance for the LEED system owing to the system's market attracting force and more green building materials and products are provided to comply with LEED credits' requirements. They also pointed out challenges for obtaining individual credits as shown in Table 2.

Practitioners highlighted some limitations and drawbacks related to the compliance of certain credits' requirements. This indicates that more development is required for the adaptation process of LEED system in the Italian context.

Table 2. Individual credit review according to LEED practitioners in the Italian context

\begin{tabular}{|c|c|c|}
\hline Credit & $\begin{array}{c}\text { No. } \\
\text { participants }\end{array}$ & Challenge \\
\hline $\begin{array}{l}\text { SS: pre } 1 \\
\text { Construction } \\
\text { activity pollution } \\
\text { prevention }\end{array}$ & 2 & $\begin{array}{l}\text { This requirement is not included in the Italian code but it is a prerequisite in the } \\
\text { LEED scorecard. Hence, it is considered an additional challenge to comply with } \\
\text { this prerequisite's requirements. }\end{array}$ \\
\hline $\begin{array}{c}\text { SS C3 Brownfield } \\
\text { development }\end{array}$ & 2 & $\begin{array}{l}\text { Incentives and technical requirements provided for developing brownfield sites } \\
\text { vary from one region to another, thus the feasibility of this credit should be } \\
\text { analyzed case by case. }\end{array}$ \\
\hline $\begin{array}{l}\text { SS C4 Alternative } \\
\text { transportation }\end{array}$ & 4 & $\begin{array}{l}\text { This credits is relatively easy to obtain in the Italian context owing to the } \\
\text { proximity of public means of transportation and promoting cleaner } \\
\text { transportation alternatives, but particularly SS C4.4 (reduce parking and } \\
\text { encourage car share services) is considered easier to achieve for office and } \\
\text { institutional buildings compared to multifamily buildings. }\end{array}$ \\
\hline
\end{tabular}


Table 2. Individual credit review according to LEED practitioners in the Italian context (Continued)

\begin{tabular}{|c|c|c|}
\hline Credit & $\begin{array}{l}\text { No. } \\
\text { participants }\end{array}$ & Challenge \\
\hline $\begin{array}{l}\text { SS C6 Storm water } \\
\text { Management }\end{array}$ & 2 & $\begin{array}{l}\text { This is considered a difficult credit to obtain for many practitioners due to the } \\
\text { calculation requirements for the stormwater quantity and quality management. } \\
\text { Also, practitioners indicated that SS C6.2 (Quality Control) is expensive to } \\
\text { achieve. }\end{array}$ \\
\hline $\begin{array}{l}\text { SS C8 Light } \\
\text { pollution reduction }\end{array}$ & 1 & $\begin{array}{l}\text { This credit depends on client's decision. Some regions in Italy require reducing } \\
\text { outdoors light pollution. Yet, LEED credit's requirements are considered more } \\
\text { stringent than regional mandates. }\end{array}$ \\
\hline $\begin{array}{l}\text { WE pre1 and C1 } \\
\text { Water use } \\
\text { reduction }\end{array}$ & 2 & $\begin{array}{l}\text { Achieving } 40 \% \text { reduction in water use can be done by using efficient irrigation } \\
\text { and landscape practices, but it is difficult to achieve } 100 \% \text { reduction which } \\
\text { requires reuse of rainwater or treated grey water that are considered expensive } \\
\text { technologies if not supported by local incentives. }\end{array}$ \\
\hline $\begin{array}{l}\text { WE C2 Water } \\
\text { efficient } \\
\text { landscaping }\end{array}$ & 2 & $\begin{array}{l}\text { This credit depends on project type, context and incentives offered. High first- } \\
\text { cost is associated with on-site sewage treatment and/or grey water treatment and } \\
\text { reuse, but some regional norms require the reuse of storm water. }\end{array}$ \\
\hline $\begin{array}{l}\text { EA P1 and EA C3 } \\
\text { Commissioning }\end{array}$ & 2 & $\begin{array}{l}\text { Commissioning services are considered relatively expensive in the Italian } \\
\text { context. }\end{array}$ \\
\hline $\begin{array}{l}\text { EA C1 Optimize } \\
\text { energy } \\
\text { performance }\end{array}$ & 4 & $\begin{array}{l}\text { This credit depends on building type and context. It requires an expert } \\
\text { contribution to perform the simulation processes which vary in their fees } \\
\text { depending on the context and the required technical expertise. Yet, experts } \\
\text { indicated that using LEED U.S. (conforming to ASHRAE) is easier to achieve } \\
\text { than LEED Italia (conforming to UNI norms). }\end{array}$ \\
\hline $\begin{array}{l}\text { EA C2 On site } \\
\text { renewable energy }\end{array}$ & 2 & $\begin{array}{l}\text { This credit requires high initial cost, although promoting renewable energy is a } \\
\text { national target providing incentives for photovoltaic energy production, but they } \\
\text { are not enough to satisfy the required threshold for project energy demand as } \\
\text { required by LEED credit. }\end{array}$ \\
\hline $\begin{array}{l}\text { EA C4 Enhanced } \\
\text { refrigerant } \\
\text { management }\end{array}$ & 1 & $\begin{array}{l}\text { This requirement is easier for institutional or high-rise multifamily buildings } \\
\text { due to HVAC specification. }\end{array}$ \\
\hline $\begin{array}{l}\text { EA C5 } \\
\text { Measurement and } \\
\text { verification }\end{array}$ & 1 & $\begin{array}{l}\text { This credit's requirements are mandated by the national legislations but it is } \\
\text { considered more difficult for multifamily houses because it necessitates } \\
\text { metering each residential unit. }\end{array}$ \\
\hline $\begin{array}{l}\text { EA C6 Green } \\
\text { power }\end{array}$ & 2 & $\begin{array}{l}\text { Regulations and incentives to achieve this credit's requirements differ from one } \\
\text { region to another. }\end{array}$ \\
\hline $\begin{array}{l}\text { MR C7 Certified } \\
\text { wood }\end{array}$ & 2 & $\begin{array}{l}\text { This credit's requirements depend on the availability of certified wood with } \\
\text { considerable prices in the context. Forest Stewardship Council (FSC) certified } \\
\text { wood products is currently available in the Italian context but it is important to } \\
\text { note that there are other types of certified wood products, e.g. Programme for } \\
\text { the Endorsement of Forest Certification (PEFC) in the Italian context as well } \\
\text { but it is not compliant with this credit's requirements. }\end{array}$ \\
\hline $\begin{array}{l}\text { IEQ C1 Outdoor } \\
\text { Air delivery } \\
\text { Monitoring }\end{array}$ & 2 & $\begin{array}{l}\text { The compliance of this credit's requirements depends on the project type and } \\
\text { budget. First-cost for installing CO2 monitors for each residential unit is } \\
\text { considered an obstacle for multifamily buildings. }\end{array}$ \\
\hline $\begin{array}{l}\text { IEQ C2 Increased } \\
\text { Ventilation }\end{array}$ & 2 & $\begin{array}{l}\text { This credit's requirements are easier to implement in mechanically ventilated } \\
\text { buildings because they are carefully planned to achieve increased ventilation } \\
\text { rates. }\end{array}$ \\
\hline $\begin{array}{l}\text { IEQ C5 Indoor } \\
\text { Chemical and } \\
\text { Pollutant Source } \\
\text { Control } \\
\end{array}$ & 1 & $\begin{array}{l}\text { This credit's requirements require the use of MERV } 13 \text { filters across air } \\
\text { handling units which may not be feasible for mid-rise multifamily buildings. }\end{array}$ \\
\hline
\end{tabular}




\section{Research Findings and Conclusions}

LEED system acts as a 'sustainable project management' as well as a 'sustainable building certification and market tool'. Yet, it is more important to know how to use the tool properly considering its main goals along with its limits of operation especially in a foreign context, e.g. applying LEED system in the Italian context with stronger commitments to sustainability. Hence, the main objective of this study is to present an overall assessment for the LEED rating system in the Italian context, pointing out areas of concern for future development.

The first part of the research concludes that the Italian norms and directives have potentials to comply with LEED requirements (at least easily achieving the LEED certified level), and many times exceeding its requirements.

The second part of the research presents LEED market analysis. It shows that LEED adopts a focalized vertical market approach. It focuses more on commercial and office buildings in main cities and large scale projects, and mostly private ownership) in order to attract investments using its certification's brand name. It is achieving success as a sustainable building certification and market tool providing value and setting the price in the global marketplace through its third party certification system. It also promotes the diffusion of green innovative materials, practices and information provision in the global marketplace.

The third part of the research cites the result of a survey among LEED practitioners. It shows that assessing LEED as a 'sustainable project management tool' shows some drawbacks related to the inefficient use of the system mainly dominated by its market power and certification prestige, thus, practitioners continue to adopt a short-term rather than a long-term perspective seeking easily achieved credits. Also, although LEED process is very robust but it has been criticized for its complexity to integrate into the ordinary building process, so it has not successfully promoted "Integration" in its comprehensive sense, while exploring synergies and minimizing cost premium. In addition, some problems arise concerning the applicability of the system on various building types, scales and contexts. Hence, LEED systems needs to develop its role as a guideline and decision support tool as well as its mechanism for measuring and evaluating sustainable building performance, so that better and reliable results can improve LEED position in the global marketplace. While assessing LEED as a 'sustainable building certification and market tool' shows that the shift in the building process towards a sustainable built environment is occurring slowly and on a vertical scale focusing on some building sectors rather than others. Also, its market diffusion in the Italian context faces challenges regarding the insufficient availability of green materials satisfying LEED requirements, e.g. materials with low volatile organic compounds (VOC) and Forest Stewardship Council (FSC) certified wood products. Also due to the high soft cost of sustainability tests and expertise required, e.g. commissioning process and indoor air quality tests.
Hence, it can be concluded that practitioners criticise LEED more as a sustainable guideline tool, while researchers criticise it more as a measurement and evaluation tool for sustainable building performance, while they both agree on its market potentials.

Hence, future development of LEED system in a foreign context requires a balance between three main aspects:

- Preserving standardization of the LEED system to be able to maintain its value in the global marketplace.

- Integration with sustainable building practices and green market specific to the context, as well as exceeding local building norms and directives.

- Developing the system in a flexible and user friendly way to guarantee its wide diffusion and be able to compete in the global market.

\section{Recommendations}

The research presents a set of recommendations to develop the application of LEED Green Building Rating System as a sustainable project management and market tool in the Italian context.

\subsection{Developing LEED as a Sustainable Project Management Tool}

This comprises developing LEED to offer sustainable building guidelines that match with the local context requirements, as well as means for measuring/evaluating sustainable building performance in a standardized manner to enable comparison with other LEED certified buildings globally. This can be done through the following points:

- Develop LEED system to exceed national and local norms and directives and raise the bar for sustainable building performance.

- LEED credits should be more scientifically grounded and based more on performance rather than prescriptive measures.

- Sustainable building guidelines should be customized by geographical region, while taking into consideration any differences that may arise due to global versus local/regional credit requirements.

- Develop new tools and methods, e.g. software tools to aid assessment in a more reliable, simpler and user friendly way, encourage an integrated building process and improve the decision making process considering both national/local economic and environmental variations.

\subsection{Developing LEED as a Sustainable Certification and Market Tool}

These set of recommendations aim at developing LEED as a sustainable building third party certification tool. They also aim at encouraging national sustainable market transformation of green building materials and products. This can be done through better integration with the local context from one hand and maintaining international standardization from the other hand. This can be done through the following points; 
- LEED system should make use of the potentials offered in the European market related to energy efficiency, e.g. green labeling and energy certification systems, in addition to new technologies and specialized products able to meet sustainable requirements.

- It is important to avoid mandating specific green certified materials (e.g. FSC wood) rather than others (PEFC wood) or else this would endanger the whole process to a kind of market monopoly.

- More research is needed to support the business case for green buildings in the Italian context, the cost premium of applying the LEED process, and the payback time for sustainable strategies recommended by LEED credits.

- It is important to maintain wider diffusion in the global marketplace through developing Memorandum of Understanding (MOU) with other green building rating systems to guarantee setting a common ground for assessment and maintain consistency in the global marketplace, as well as developing international standard protocols, and open up new regional chapters.

\section{Acknowledgements}

The author would like to thank professor Monica Lavagna, from the Politecnico di Milano, as well as arch. Paola Moschini, eng. Viviana Patton and arch. Carlotta Cocco for their help and support during the research.

\section{References}

Berardi, U. (2011). Sustainability Assessment in the Construction Sector: Rating Systems and Rated Buildings, John Wiley and Sons, Ltd and ERP Environment.

Bevini, F. (2009). Italy: Green Building Market, the U.S. Commercial Service 800-USA-TRADE.

Eijadi, D., Vaidya, P., Reinertsen, J., and Kumar, S. (2002). Energy and Environmental policy, Introducing Comparative Analysis to the LEED System: A Case for Rational and Regional Application,

http://eceee.org/library/conference_proceedings/ACE EE_buildings/2002/Panel_9/p9_7/paper.

ENERBUILD (2010). WP 6.1 - Transnational comparison of instruments according to ecological evaluation of public buildings.

Fowler, K. M. and Rauch, E. M. (2006). Sustainable Building Rating Systems Summary, the Pacific Northwest National Laboratory.
IFMA Foundation (2010). Sustainability Guide-Green Building Rating Systems.

Inbuilt Ltd (2010). BREEAM versus LEED

International Energy Agency (IEA) (2010). Energy Performance Certification of Buildings - IEA POLICY PATHWAY

Issa, M. H., Rankin, J. H., and Christian, A. J. (2010). Canadian practitioners' perception of research work investigating the cost premiums, long-term costs and health and productivity benefits of green buildings, Elsevier Ltd.

Lacroix, S. (2010). Understanding LEED pioneering environmental stewardship.

Lavy, S. and Fernández-Solís, J. L. (2009). "LEED Accredited Professionals' perceptions affecting credit point adoption”, Facilities, 27(13/14), 531-548.

Marszal, A. J. (2011). Life Cycle Cost Optimization of a BOLIG + Zero Energy Building, Aalborg University.

McManus, B. (2010). Green Buildings Certifications, White Paper.

Ministry for the environment and Territory (2013). Environmental Action Strategy for sustainable development in Italy.

OECD/ IEA (2009). Energy policies of IEA Countries, Italy 2009 Review.

Rahardjati, R., Khamidi, M. F., and Idrus, A. (2011). Green Building Rating System: The need of Material Resources Criteria in Green Building Assessment, 2nd International Conference on Environmental Science and Technology (ICEST) IEEE.

Smith, T. M., Fischlein, M., Suh, S., and Huelman, P. (2006). Green Building Rating Systems, A comparison of the LEED and Green Globes systems in the US.

Steelcase WorkLab (2009). Understanding LEED Version 3.

Stein, J. and Reiss, R. (2004). Ensuring the Sustainability of Sustainable Design, What Designers Need to Know About LEED, E Source, AED.

USGBC (2009). LEED 2009 for New Construction and Major Renovations.

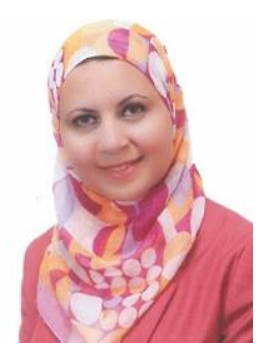

Walaa S. E. Ismaeel is currently a lecturer at the Department of Architectural Engineering at the British University in Egypt (BUE) and a member at the Centre of Sustainability and Future Studies, also a LEED AP BD+C since 2009with international academic and practical experience in the field of Green buildings. 